\title{
Optimization of Pipe Finning Process with Engineering Principles
}

\author{
Kiran Ashok Salunke ${ }^{1}$, Vishakha Lambhate ${ }^{2}$, Utkarsha Jadhav ${ }^{3}$, Saurabh Kumbhar ${ }^{3}$ \\ 1, 2, 3, ${ }^{4}$ B.E (Mechanical), Department of Mechanical Engineering, \\ STES's NBN Sinhgad College of Engineering, Ambegoan(bk),Pune-411041,Maharashtra, India \\ Savitribai Phule Pune University
}

\begin{abstract}
Industrial development depends on total process time of each process and investment on the same i.e mass is the production vast is the output. Thus by reducing time between processes with minimum use of manpower, electricity can bring rise in total output and profit. This paper shows an overview of use of 5 s principle for arranging a layout and design principles to built a trolley. With reduced cycle time, backtracking we have optimized the process. Application of trolley between to process can achieve our purpose of reduced cycle time, we can monitor movement of assemblies and product between different stations .Material handling time is one of the concern in many industries like us, so by using simple design trolley can be major outbreak. Our benchmark has been a less space consuming, easy to handle and more resistant trolley.
\end{abstract}

Keywords: CAD, 5S, PDCA, Trolley

\section{Introduction}

Generally, for a task to be productive we need simple path. Simpler the path higher the output .A systematic arrangement of machinery for productive output with minimum backtracking and minimum stack-up time. A layout using $5 \mathrm{~s}$ system PDCA cycle successfully leaded us to optimized process. This included total survey of pipe finning process , the time taken by each process and total manpower required.

Traditionally our industry used to use overhead cranes for all material handling work. For example if we have to move our assembly from bending station to welding station, only option was overhead crane. This resulted in subsequent time loss and man power. Implementation of trolley for material handling purpose will dissolve the time loss and make material handling simple.

Due of feasible design of trolley, we are capable of easy assembly and disassembly of trolley. Hence better space utilization and better resource management. Use of rollers for movement of trolley within our workshop has proved a ultimate add-on for workers, as they can move heavy assemblies in numbers without much effort and cranes from one station to another in any direction. By utilizing features of solid-works CAD software we were to able present a detailed and excellent model of our trolley .On the whole, trolley is easy to dismantle and assemble, easy to move, high load carrying capacity (1 ton) and conforms to safety measures. The design sheet will ultimatetly help to simply manufacturing process. Thus aim of trolley which is to minimize material handling time and manpower is achieved.

\section{Objective}

To optimize the pipe finind assembly process for reduction in process time , manpower required, back tracking by using engineering processes liks 5s system, PDCA cycle and designing a assembling disassembly trolley for material purpose.

\section{Methodology}

\subsection{5 s system}

The 5S practices are needed for well-organized and neat work places, standardization \& the discipline to implement quality standards.5S are the fundamental requirements for producing high quality products avoiding waste and achieving the high productivity. $5 \mathrm{~S}$ consist of the following five simple steps:-

- SEIRI (Sort): By finding the problem related to handling we sorted the machines according to our convinence. Also we arranged the raw matrial and scrap parts in a orderly manner.

- SEITON (Systematic arrangement): arranging machines in proper order by no backtracking.

- SEIKETSU (Standardize): We studied the whole process and presented a standard layout . Layout with less cycle time , stack up time and man hours.

- SEISO (Shine and inspect): keep the premises clean and inspect process at regular intervals.

- SHITSUKU(Sustain \& Self-discipline): We presented the result of layout

consisting of efficiency, its area included and total saving. In order to ensure the change remains implemented. Also the process is continues and is disciplined.

Design of trolley and implementation of same.

Calculations of overall time of process of successful implementation of Ideas.

\subsection{Cause \& effect diagram}

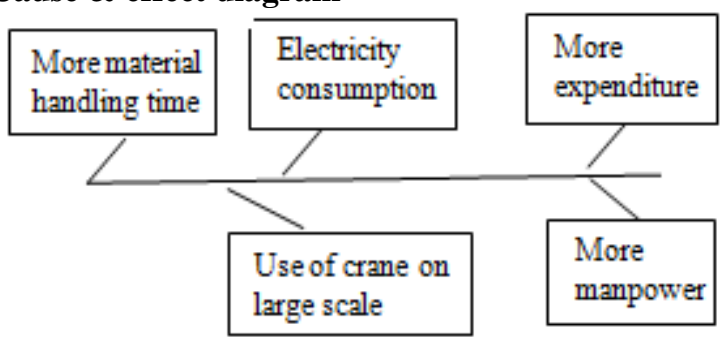

Figure 1: Cause and effect diagram 


\section{International Journal of Science and Research (IJSR) \\ ISSN (Online): 2319-7064}

Index Copernicus Value (2013): 6.14 | Impact Factor (2014): 5.611

\section{Previous Layout}

TIME PHASE

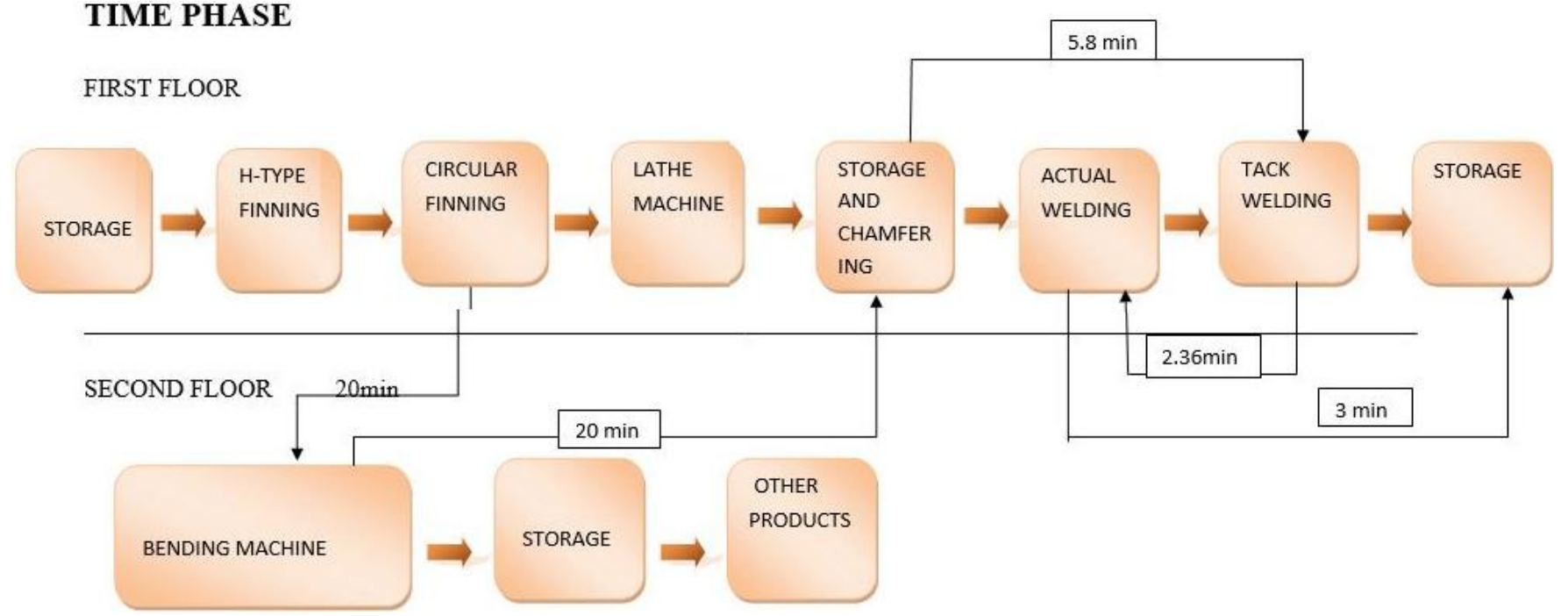

Figure 2: previous layout - showing material handling time

\section{Current layout}

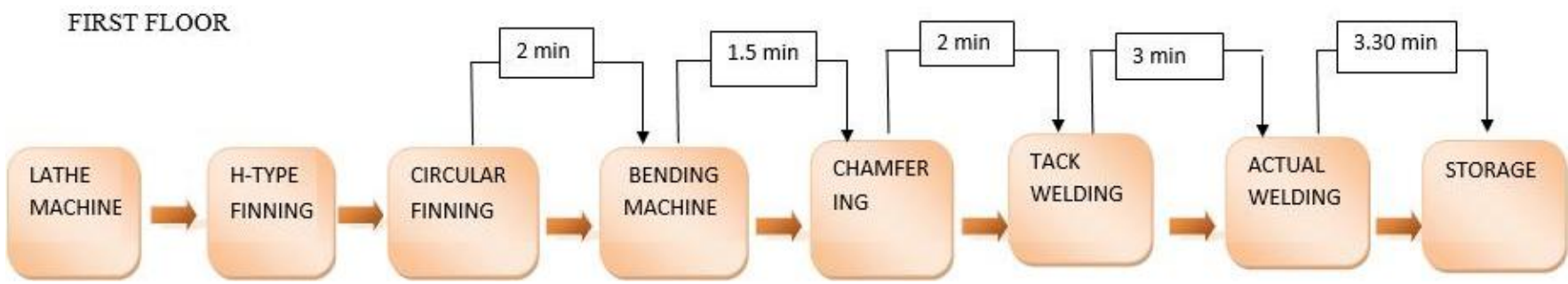

Figure 3: current layout with optimization

\section{Study Chart of profits from layout}

Study chart gives an overview of total saving in terms of energy ,manpower and money .

\begin{tabular}{|c|c|c|c|c|}
\hline S. No & parameters & old layout & recent layout & current layout \\
\hline 1 & cycle time & $50 \mathrm{~m} 48 \mathrm{sec}$ & $18 \mathrm{~m} 56 \mathrm{sec}$ & $11 \mathrm{~m} \mathrm{60sec}$ \\
\hline 2 & man hours & $2 \mathrm{~h} 41 \mathrm{~m}$ & $2 \mathrm{~h} 6 \mathrm{~m}$ & $2 \mathrm{~h} 1 \mathrm{~m}$ \\
\hline 3 & & $\begin{array}{c}\text { Rs } 80 /(10 \\
\text { cycles })\end{array}$ & $\begin{array}{c}\text { Rs 20.07/(10 } \\
\text { cycles) }\end{array}$ & Rs $20 /(10$ cycles $)$ \\
\hline \multicolumn{5}{|c|}{$\begin{array}{l}\text { Money saved - } \\
\text { 1)Worker } \\
\text { For } 8 \text { hours }=700 \text { ruppees } \\
\text { For } 40 \text { min }=60 \text { ruppes (saving) } \\
\text { 2)Electricity } \\
\text { Previous layout }=\text { Energy } \\
\text { consumed=10.5505KW*0.84hrs* } 10=88.6424 \text { ruppe } / 10 \mathrm{CYclE} \\
\text { New layout }=\text { Energy consumed }=10.5505 \mathrm{KW} * 0.19 \mathrm{hrs} * 10 \\
=20 \text { ruppe/cycle }=20 \mathrm{rps} / 10 \text { cycle }\end{array}$} \\
\hline
\end{tabular}

Figure 4: study chart after optimum layout

\section{Trolley Design}

Objective behind trolley is to reduce material handling time and to promote faster cycles. Using certain defined steps we have build a trolley much safer and compact to handle for assembly handling purposes. A trolley which can reach any place with the help of rollers is an advantage .carrying capacity of 1 Ton makes it reliable for heavy loads.

\subsection{Procedure of Design}

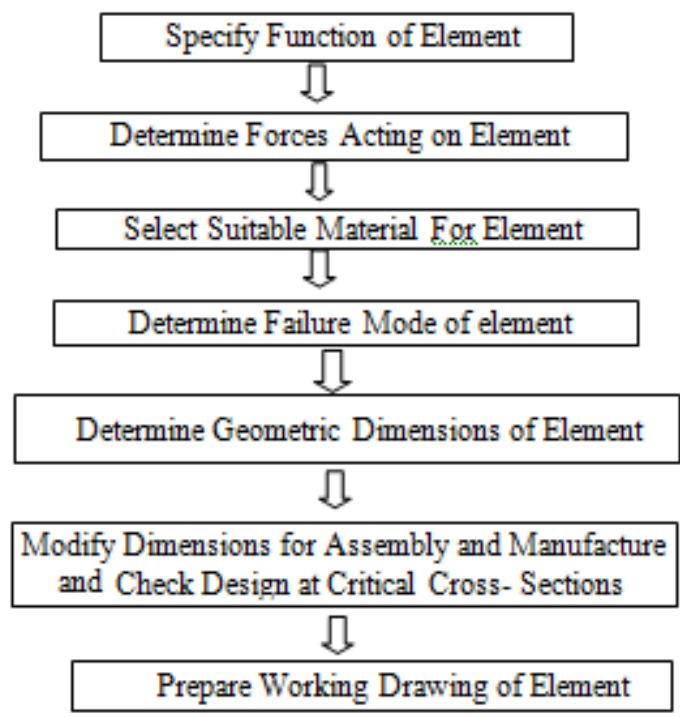

Figure 5: Steps for Design process 


\section{International Journal of Science and Research (IJSR)}

ISSN (Online): 2319-7064

Index Copernicus Value (2013): 6.14 | Impact Factor (2014): 5.611

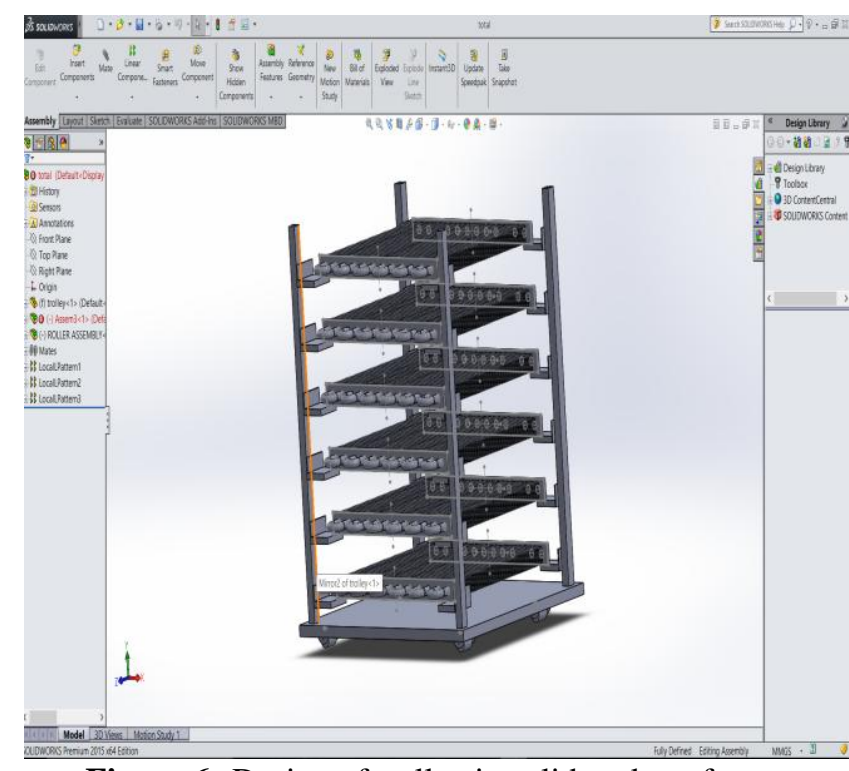

Figure 6: Design of trolley in solidworks software

Designing in CAD software is the preliminary stage foer a design . Helps to express our ideas in a visual way. After modelling the real desgining started taking help of above steps Implementation of trolley will make a huge impact on process time and convenience for workers. The study showing the positive imoact of trolley on material handling is shown below.

\subsection{Study chart after implementation of trolley}

\begin{tabular}{|c|c|c|c|}
\hline Sr No & Parameters & Old Operation & Current Operation \\
\hline 1 & Cycle time & $3.29 \mathrm{hrs}$ & $1.14 \mathrm{hrs}$ \\
\hline 2 & $\begin{array}{c}\text { Man hours } \\
\text { for } 2 \mathrm{hrs}\end{array}$ & $\begin{array}{l}3.29 \mathrm{hrs} / \mathrm{person} \\
3.29 * 2=6.58 \mathrm{hrs}\end{array}$ & $1.14 \mathrm{hrs}$ \\
\hline
\end{tabular}

\begin{tabular}{c|c} 
Money saved on workers & $\begin{array}{c}\text { Money saved on electricity } \\
\text { old operation: }\end{array}$ \\
For 1 hours $=87.5 \mathrm{rs} /$ person & $\begin{array}{c}\text { ld } \\
\text { For } 2 \text { persons }=\end{array}$ \\
$87.5 * 2=175$ rupees/hr & $34.711 * 30=$ Rs $1041.33 /$ month \\
For 3.29 hrs & $1041.33 * 12=$ Rs $12495.96 /$ yr \\
$=3.29 * 175$ & \\
$=575.75 R s /$ day & Current operation \\
Per year expenditure & Since no use of crane so no \\
$=$ Rs 207270 & expenditure on electrical energy. \\
Savings $\backslash$ Per person & Hence money saving is \\
expenditure=Rs 35910 & $=$ Rs 12495.95 \\
Using trolley only one person & \\
required so saving per year & \\
is=Rs 171360 &
\end{tabular}

Figure 7: Study chart of process after implementation of trolley

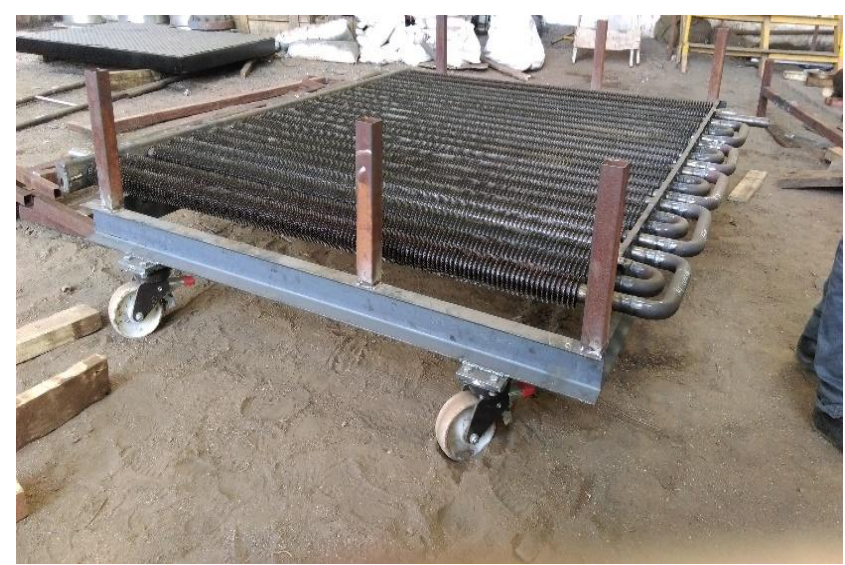

Figure 8: Actual picture of trolley

\section{Results and Conclusions}

Two strategies which we used to optimize the pipe finning assembly process were firstly arranging the layout of process in order using $5 \mathrm{~S}$ system. Result of optimizing the layout was a total savings of Rupees 20/cycle. Also due to better ,simpler layout resulted in more friendly environment . Secondly, Use of trolley for material handling of finned pipes and assemblies between various stations helped to eliminate the use of crane and reduce material handling time. Reduced electricity bill and manpower for process cycle was a success .money saved on workers is 171360 /year and on electricity is 12495.95 rupees.

\section{References}

[1] Kaustubh .V.Wankhade And Dr. N.A.Wankhade "Design and analysis of transfer trolley for material handling - a review" IJAIEM , Volume 4, Issue 2, February 2015.

[2] Arash Ghodrati, Norzima Zulkifli "The Impact Of 5S Implementation On Industrial Organizations' Performance", March. 2013

[3] V B Bhandari "Design Of Machine Elements", $3^{\text {rd }}$ edition McGraw Hill Publication

\section{Author Profile}

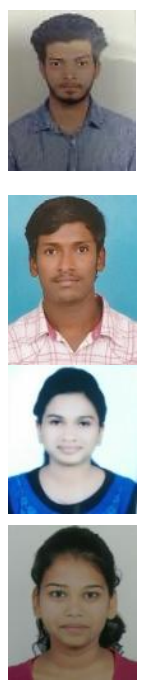

Kiran Ashok Salunke is pursuing his final year Mechanical engineering from NBN Sinhgad school of Engineering, Ambegoan(Bk). Area of interest is Automobile design

Sourabh Kumbhar is pursuing his final year Mechanical Engineering from NBN Sinhgad School of Engineering, Ambegoan(Bk).

Utkarsha Jadhav is pursuing his final year Mechanical Engineering from NBN Sinhgad School of Engineering, Ambegoan(bk).

Vishakha Lambhate is pursuing his final year Mechanical Engineering from NBN Sinhgad School of Engineering, Ambegoan(bk) 